\title{
FORMULATION AND EVALUATION OF POLYMER EFFECT ON in-vitro KINETICS OF SUSTAINED RELEASE MATRIX TABLETS OF CARVEDILOL USING MODEL DEPENDENT METHODS
}

Umme Rahela, Md. Mizanur Rahman Moghal', Syed Masudur Rahman Dewan, Mohammad Nurul Amin

Department of Pharmacy, Noakhali Science and Technology University, Sonapur, Noakhali3814, Bangladesh

\begin{abstract}
The present study was designed to evaluate the polymeric effect of METHOCEL K15MCR on the sustained release drug product of Carvedilol. Carvedilol matrix tablets were formulated by direct compression method using METHOCEL K15MCR polymer in various percentages. Physical parameters were tested and the dissolution procedure was performed by using USP (II) paddle method for eight hours to examine the release kinetics. In the study, METHOCEL K15MCR polymer was found to cause the strong retardation of the drug release. The release mechanism was explored and explained with zero order, first order, Higuchi and Korsmeyer-Peppas equations. In the context, it can be suggested with a satisfactory result that this sustained release Carvedilol tablets can be marketed to treat patient ensuring proper healthcare.
\end{abstract}

Keywords: Carvedilol, Sustained release drug, Methocel, Matrix tablet, Higuchi equation, Korsmeyer-Peppas.

*Corresponding author:

Md. Mizanur Rahman Moghal

Assistant Professor

Department of Pharmacy

Noakhali Science and Technology University

Sonapur, Noakhali- 3814

Bangladesh

E-mail: pharmamizan@ymail.com

Contact No.: +8801190314094 


\section{Introduction}

Carvedilol is a nonselective antihypertensive drug, used for treating high blood pressure and mild to moderate conjestive heart failure. The aim of our present study was to formulate sustained release matrix tablet of Carvedilol using METHOCEL and evaluate its release profile to justify the formulation.

Sustained drug delivery involves the application of physical and polymer chemistry to produce well characterized and reproducible dosage forms, which control drug entry into the body within the specifications of the required drug delivery profile. In this type of dosage forms, the rate of drug release mainly controlled by the delivery system itself, though it may be influenced by external conditions, like $\mathrm{pH}$, enzymes, ions, motility and physiological conditions ${ }^{1}$.Sustained release tablets and capsules are commonly taken only once or twice daily, compared with counterpart conventional forms that may have to take three or four times daily to achieve the same therapeutic effect ${ }^{2}$. Typically, sustained release products provide an immediate release of drug that promptly produces the desired therapeutic effect, followed by gradual release of additional amounts of drug to maintain this effect over a predetermined period. The drug release from matrix tablet depends on other factors such as pore permeability, shape and size of matrix, drug solubility, polymer molecular weight, drug loading, compression force, and hydrodynamic conditions ${ }^{3.4}$. Previous studies developed by Williams et $a l^{5}$ led to the conclusion that the type and level of excipients influence the rate and extension of drug release.

\section{Materials and Methods}

\section{Materials}

The ingredients and the equipments used in the formulations are mentioned in Table 1 and Table 2 respectively.

Table 1: List of active ingredient and other excipients used in the preparation of matrix tablets

\begin{tabular}{|c|c|c|c|}
\hline Name & Category & Source & Country \\
\hline Carvedilol & Active ingredient & Silva & Merck, Germany \\
\hline Lactose & Filler, Diluent & Colorcon & USA \\
\hline Mg stearate & Antiadherent & Colorcon & USA \\
\hline Avicel & Disintegrant & Colorcon & USA \\
\hline Povidone & Binder & Colorcon & USA \\
\hline Talc & Lubricant & Colorcon & USA \\
\hline Methocelk15 MCR & Matrix forming & Colorcon & USA \\
\hline
\end{tabular}


Table 2: List of equipments used in the method of Carvedilol SR tablets

\begin{tabular}{|c|c|c|c|}
\hline Name & Model & Source & Country \\
\hline Sieve & - & Endecotts, Test Sieve & UK \\
\hline Compression Machine & Manesty D type & - & UK \\
\hline Electronic Balance & AR2140 & OHAIS & Switzerland \\
\hline Digital pH meter & $\mathrm{pH} 209$ & HANNA & Romania \\
\hline Shaker & $\begin{array}{c}\text { Power Sonic } \\
505\end{array}$ & Hwashin Technology & South Korea \\
\hline Hardness tester & $\mathrm{EH}-01 \mathrm{P}$ & Electro Lab & India \\
\hline Fribilator & EF-2 & Electro Lab & India \\
\hline Dissolution Tester & TDT-08L Plus & Electro Lab & India \\
\hline UV-Spectrophotometer & UV-1800 & Shimadzu Corporation & Japan \\
\hline
\end{tabular}

\section{Preparetion of matrix tablet-Carvedilol}

The tablets of each batch were prepared by direct compression method. In all the formulation the weight of the active ingredient, Carvedilol $6.25 \mathrm{mg}$ and the total weight were adjusted to $180 \mathrm{mg}$ (Table 3). At first the active ingredient and other excipients and polymer were accurately measured. Blending was then done following proper mixing with uniformity using a mortar. The API matrix forming polymer METHOCEL K15 MCR was then added, after that milling of the mixed ingredient was performed. At last talc, Mg stearate, avicel were added to the formulation. In the formulation technique the compression force was 3.5 ton.12 $\mathrm{mm}$ flat die was used in this tablet formulation.

Table 3: Different formulation of Carvedilol Sustained Released tablets

\begin{tabular}{|c|c|c|c|c|}
\hline Ingredients & $\begin{array}{c}\text { CMK15F1 } \\
\mathbf{m g}\end{array}$ & $\begin{array}{c}\text { CMK15F2 } \\
\mathbf{m g}\end{array}$ & $\begin{array}{c}\text { CMK15F3 } \\
\mathbf{m g}\end{array}$ & $\begin{array}{c}\text { CMK15F4 } \\
\mathbf{~ m g}\end{array}$ \\
\hline Carvedilol & 6.25 & 6.25 & 6.25 & 6.25 \\
\hline Methocel K15MCR & 60 & 54 & 45 & 36 \\
\hline Lactose & 40 & 55 & 51.75 & 57.75 \\
\hline Mg Stearate & 3 & 2 & 3 & 3 \\
\hline Avicel & 33.50 & 30 & 42 & 30 \\
\hline Povidone & 35.25 & 30.75 & 30 & 45 \\
\hline
\end{tabular}




\begin{tabular}{|c|c|c|c|c|}
\hline Talc & 2 & 2 & 2 & 2 \\
\hline
\end{tabular}

\section{Evaluation of Tablets}

\section{Length, width, size and shape}

The length and width of tablets depends on the die and punches selected for making the tablets. The tablets of various sizes and shapes are prepared but generally they are circular with either flat or biconvex faces. Here we prepared round cylindrical shape tablets.

\section{Thickness}

The thickness of a tablet can vary without any change in its weight. This is generally due to the difference of density of granules, pressure applied for compression and the speed of compression. The thickness of the tablets was determined by using a Digital Caliper (range 0-150 mm).

\section{Uniformity of weight}

It is desirable that every individual tablet in a batch should be in uniform weight and weight variation within permissible limits. If any weight variation is there, that should fall within the prescribed limits (generally $\pm 10 \%$ for tablets weighing $130 \mathrm{mg}$ or less, $\pm 7.5 \%$ for tablets weighing 130 to $324 \mathrm{mg}$ and $\pm 5 \%$ for tablets weighing more than $324 \mathrm{mg})^{6}$.

The weights of 10 tablets of each batch were taken at individually and calculate the average weight of 10 tablets. The weights were determined by using an electronic balance (Adventurer TM electronic balance, Model AR2140, Capacity (Max) - $210 \mathrm{gm}$, Readability $0.0001 \mathrm{gm}$ ). Then determine the percentage of weight variation of each tablet by using following formula.

Percentage of weight variation $=\{$ (Average weight - Individual weight $) /$ Average wt. $\} \times 100$

\section{Friability}

Friability test was performed to evaluate the ability of the tablets to withstand abrasion in packing, handling and transporting. The instrument used for this test is known as 'Friability Test Apparatus' or 'Friabilator'. It consists of a plastic chamber which is divided into two parts and revolves at a speed of $25 \mathrm{rpm}$. A number of tablets were weighed $\left(\mathrm{W}_{1}\right)$ and placed in the tumbling chamber which was rotated for four minutes or for 100 revolutions. During each revolution the tablets fall from a distance of six inches to undergo shock. After 100 revolutions the tablets were again weighed $\left(\mathrm{W}_{2}\right)$ and the loss in weight indicates the friability. The acceptable limits of weights loss should not be more than 1 percent?

$$
\text { Friability }=\left\{\left(\mathrm{W}_{1}-\mathrm{W}_{2}\right) / \mathrm{W}_{1}\right\} \times 100
$$

\section{Hardness}

The hardness of tablet depends on the weight of the material used, space between the upper and lower punches at the time of compression and pressure applied during compression. The hardness also depends on the nature and quantity of excipients used during compression. 
The hardness of the tablets was determined by using a hand operated hardness tester apparatus (Electrolab, EH-01P). A tablet hardness of about 6-8 kg-ft was considered for mechanical stability ${ }^{6}$. If the finished tablet is too hard, it may not disintegrate in the required period of time and if the tablet is too soft it may not withstand the handling during packing and transporting. Therefore it is very necessary to check the hardness of tablets when they are being compressed and pressure adjusted accordingly on the tablet machine.

\section{Assay of Carvedilol}

\section{Preparation Sample Solution}

$180 \mathrm{mg}$ of crushed tablet powder (equivalent to $6.25 \mathrm{mg}$ ) was dissolved in $0.1 \mathrm{~N} \mathrm{HCl}$ solution and made the volume up to $100 \mathrm{ml}$. The solution was diluted 100 times and absorbance was taken. Then the percentage of potency was calculated by the following equation:

$$
\% \text { of Potency }=\frac{\text { Aspl } \times \text { Wstd } \times \text { Pstd } \times \text { Average weight }}{\text { Astd } \times \text { Wspl } \times \text { Label claimed value }}
$$

Where,

$$
\begin{aligned}
& A_{\text {spl }}=\text { Absorbance of Sample } \\
& W_{\text {std }}=\text { Weight of Standard } \\
& P_{\text {std }}=\text { Potency of standard } \\
& A_{\text {std }}=\text { Absorbance of standard } \\
& W_{\text {spl }}=\text { Weight of sample }
\end{aligned}
$$

\section{In-Vitro Release Studies}

$900 \mathrm{ml}$ of $0.1 \mathrm{~N} \mathrm{HCl}$ was placed into dissolution vessels and the temperature was set to $37^{0}$ C. Tablets were transferred to each vessel. Basket was immersed in media. At the end of 30 minutes $5 \mathrm{ml}$ samples were withdrawn from each vessel. The withdrawn quantity of samples was replaced by the same. The absorbance was measured at $241 \mathrm{~nm}$ by the UV spectrophotometer using $0.1 \mathrm{~N} \mathrm{HCl}$ as blank. At every 30 minutes interval $5 \mathrm{ml}$ samples were withdrawn from the dissolution vessel and replaced with fresh dissolution medium to maintain constant volume. The dissolution study was continued for 8 hours to get a simulated picture of the drug release in the in-vitro condition and drug dissolved at specified time periods was plotted as percent release versus time (hours) curve.

\section{Analysis of Release Data}

The release data obtained were treated according to zero-order (cumulative amount of drug release versus time), first order (log cumulative percentage of drug remaining versus time), Higuchi (cumulative percentage of drug release versus square root of time), and KorsmeyerPeppas (log cumulative percentage of drug release versus log time) equation models. 
Dissolution data were also fitted according to the well-known exponential equation, which is often used to describe the drug release behavior from polymeric systems introduced by Korsmeyer-Peppas et al. ${ }^{8}$

$$
M_{t} / M_{\infty}=k t^{n}
$$

Where, $M_{t}$ is the amount of drug release at time $t, M_{\infty}$ is the amount of drug release after infinite time; $\mathrm{k}$ is a release rate constant incorporating structural and geometric characteristics of the tablet and $\mathrm{n}$ is the diffusion exponent indicative of the mechanism of drug release. A value of $n=0.45$ indicates Fickian (case I) release, $>0.45$ but $<0.89$ for non-Fickian (anomalous) release and $>0.89$ indicates super case II type of release. Case II generally refers to the erosion of the polymeric chain and anomalous transport (non-Fickian) refers to a combination of both diffusion and erosion controlled-drug release ${ }^{9}$.

\section{Results and Discussion}

\section{Drug content and physical evaluation of Ramipril matrix tablets}

After preparing the matrix tablets, all the tablets of the proposed formulations were subjected to various evaluation tests such as hardness, thickness, uniformity of weight, drug content and friability (Table 4).

Table 4: Physical properties of Carvedilol matrix tablets containing Methocel K15MCR

\begin{tabular}{|c|c|c|c|c|c|}
\hline Formulation & $\begin{array}{c}\text { Weight } \\
\text { variation } \\
(\%) \\
\mathbf{\pm S E M}\end{array}$ & $\begin{array}{c}\text { Hardness } \\
\mathbf{( K f )} \\
\mathbf{\pm S E M}\end{array}$ & $\begin{array}{c}\text { Thickness } \\
\mathbf{( m m )} \\
\mathbf{\pm S E M}\end{array}$ & $\begin{array}{c}\text { Drug } \\
\text { content } \\
(\%)\end{array}$ & $\begin{array}{c}\text { Friability } \\
(\%)\end{array}$ \\
\hline CMK15F 1 & $0.99 \pm 1.55$ & $6.08 \pm 0.13$ & $3.87 \pm 0.21$ & 99.98 & 0.70 \\
\hline CMK15F 2 & $0.97 \pm 0.35$ & $7.95 \pm 0.17$ & $3.71 \pm 0.22$ & 98.78 & 0.74 \\
\hline CMK15F 3 & $0.98 \pm 1.27$ & $6.10 \pm 0.18$ & $4.76 \pm 0.16$ & 99.65 & 0.75 \\
\hline CMK15F 4 & $0.98 \pm 3.35$ & $5.62 \pm 0.16$ & $4.17 \pm 0.14$ & 98.79 & 0.69 \\
\hline
\end{tabular}

Here, $\mathrm{n}=10 ; \mathrm{SEM}=$ Standard Error Mean

\section{Evaluation of in-vitro release}

It has been observed that with the decreased amount of the polymer and with the increased amount of lactose, the release of Carvedilol has been increased. The highest release percentage is $86.589 \%$ of the CMK15F4 formulation containing $20 \%$ of METHOCEL K15MCR and highest amount of lactose in 8 hours. On the other hand, the lowest percentage of release is $46.796 \%$ containing $33.33 \%$ of METHOCEL K15MCR and lowest amount of lactose in 8 hours. The rate of drug release was found to be inversely related to the amount of METHOCEL K15M CR (Table 5). 
The highest METHOCEL K15MCR containing formulation CMK15F1 also showed the highest MDT and $t_{50}$ value which indicates the rate retarding effect of METHOCEL K15M CR (Table 6). From Figure 1- 4, we can see the zero order, first order, Higuchi and KorsmeyerPeppas release kinetics of the formulated drugs respectively.

Table 5: Percentage of release of the formulated tablet Carvedilol

\begin{tabular}{|c|c|c|c|c|}
\hline Time(hrs) & CMK15F1 & CMK15F2 & CMK15F3 & CMK15F4 \\
\hline 0 & 0 & 0 & 0 & 0 \\
\hline 1 & 13.73599 & 19.46474 & 14.25678 & 25.45389 \\
\hline 2 & 23.44702 & 28.0358 & 28.78807 & 43.82315 \\
\hline 3 & 30.40108 & 39.54033 & 38.24268 & 59.68391 \\
\hline 4 & 38.12116 & 44.68174 & 44.15371 & 66.51971 \\
\hline 5 & 43.50199 & 49.6575 & 49.39421 & 75.29729 \\
\hline 6 & 44.18264 & 52.80976 & 53.45931 & 82.37649 \\
\hline 7 & 45.22785 & 54.91031 & 55.43472 & 83.71754 \\
\hline 8 & 46.79602 & 58.82785 & 59.48117 & 86.58915 \\
\hline
\end{tabular}

Table 6: MDT and $t_{50}$ value of the drug Carvedilol

\begin{tabular}{|c|c|c|}
\hline Formulation & MDT (hr) & $\mathbf{t}_{50}$ (hr) \\
\hline CMK15F 1 & 11.07 & 9.32 \\
\hline CMK15F 2 & 7.92 & 6.57 \\
\hline CMK15F 3 & 6.85 & 5.4 \\
\hline CMK15F 4 & 2.72 & 2.39 \\
\hline
\end{tabular}




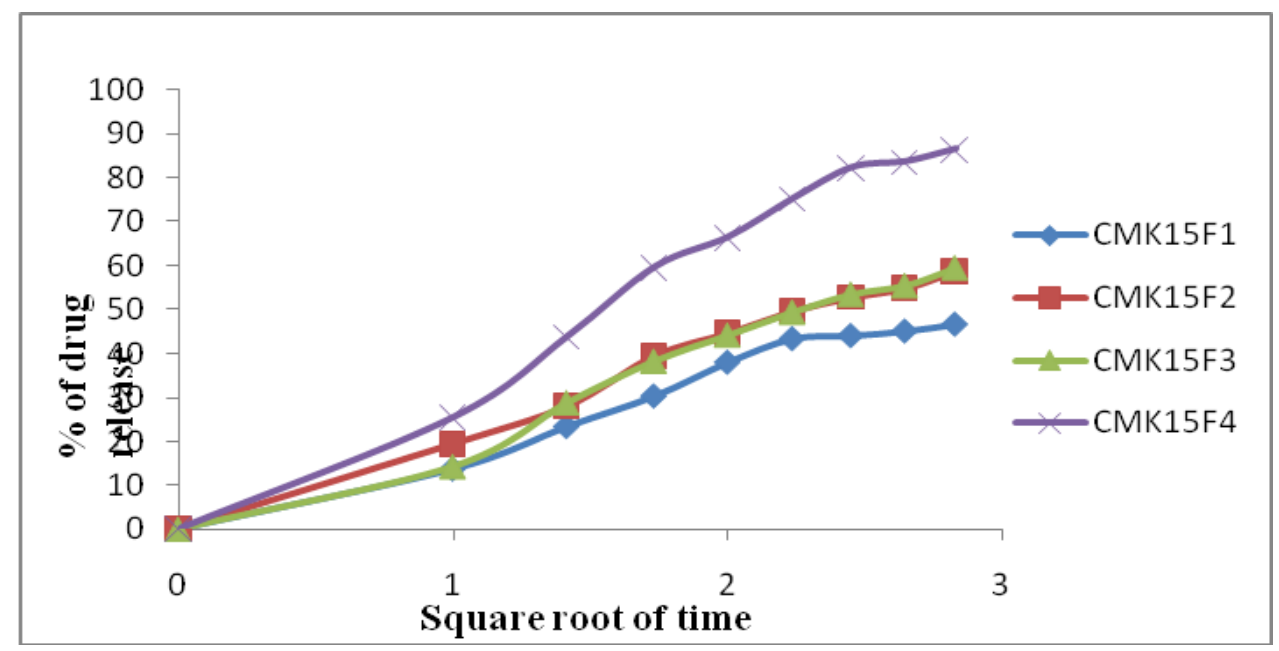

Figure 1: Zero order release kinetics of Carvedilol from METHOCEL K15MCR matrices

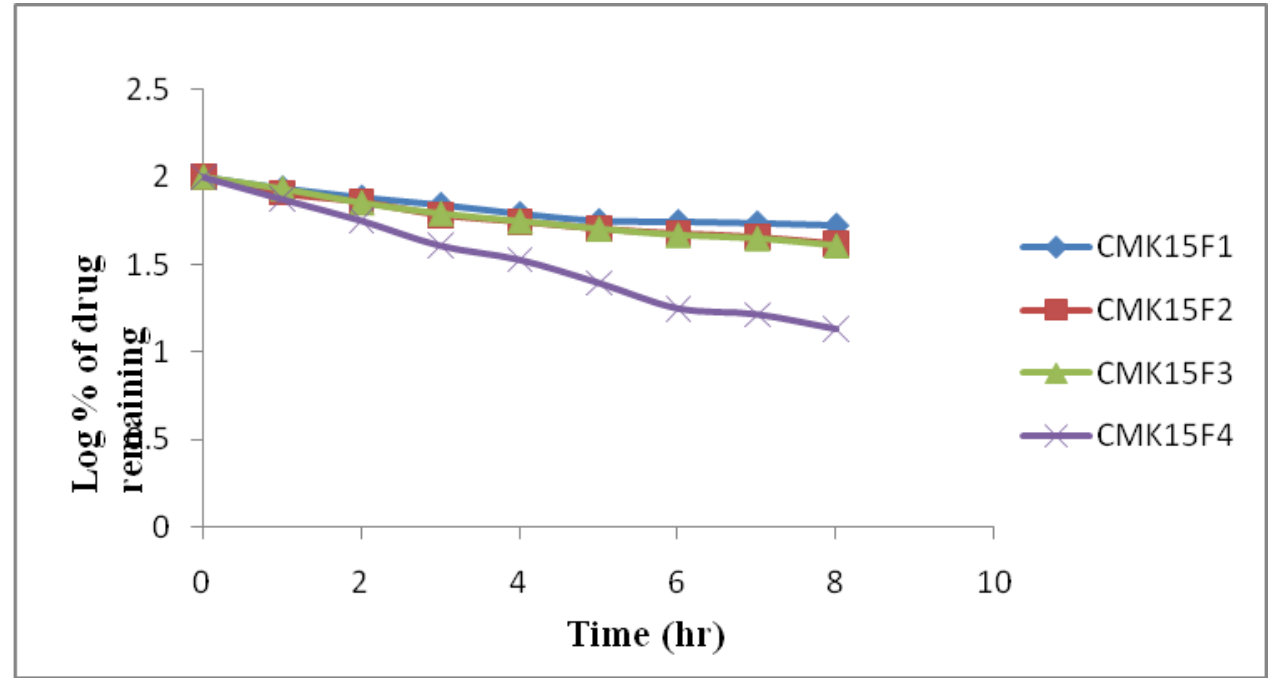

Figure 2: First order release kinetics of Carvedilol from METHOCEL K15MCR matrices

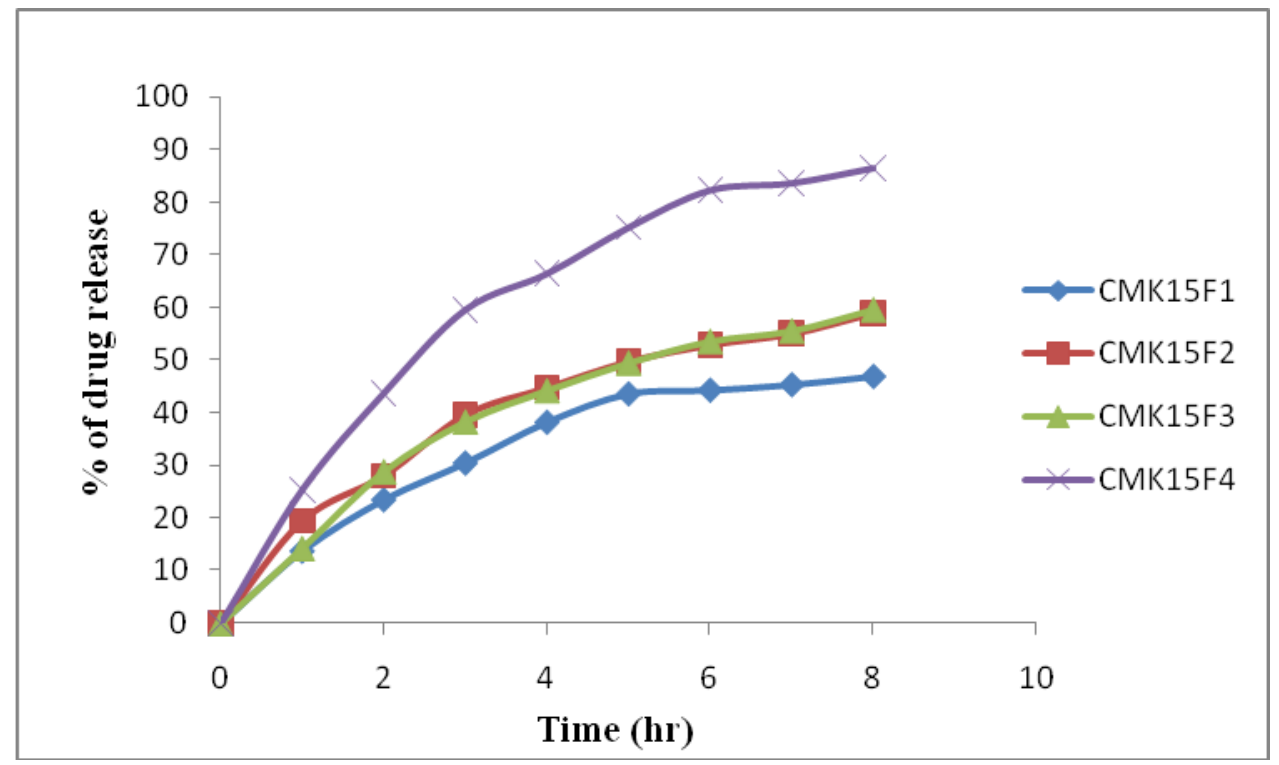

Figure 3: Higuchi release kinetics of Carvedilol from METHOCEL K15MCR matrices 


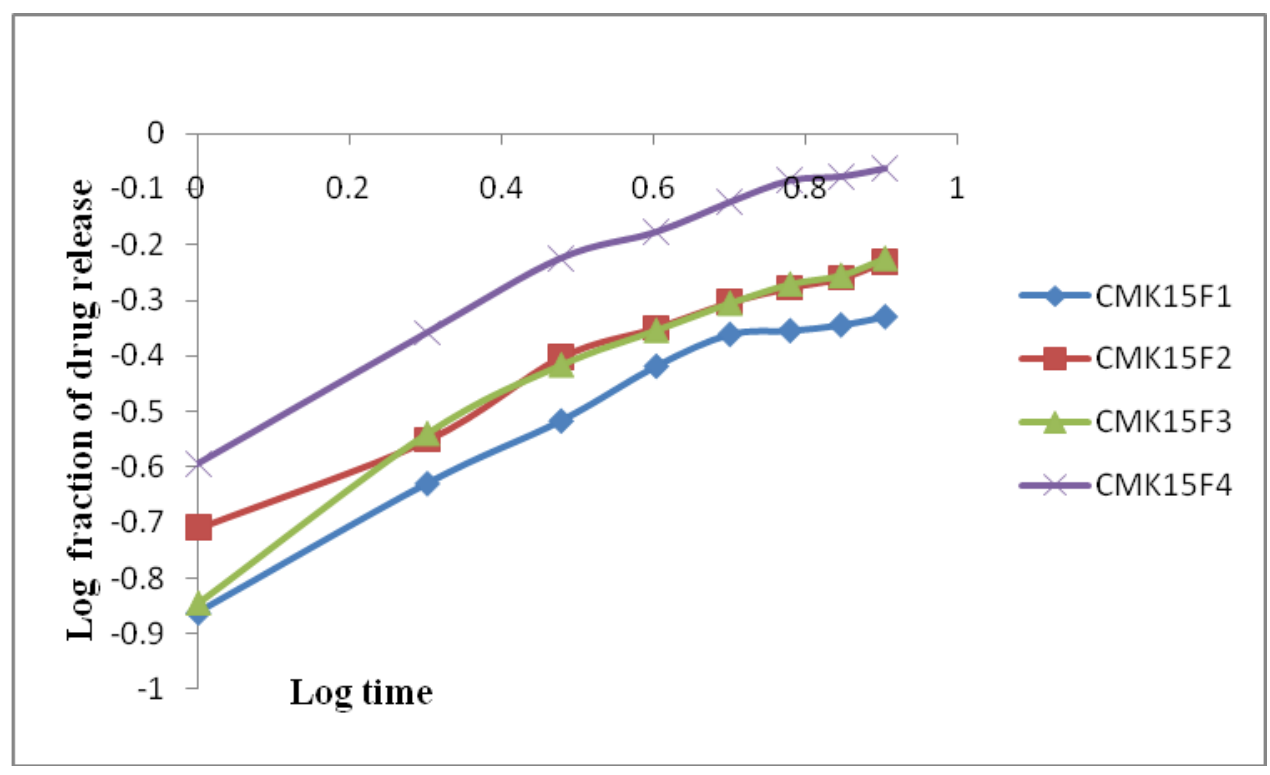

Figure 4: Korsmeyer- Peppas release kinetics of Carvedilol from METHOCEL K15MCR matrices

\section{Conclusion}

The study reveals that it is possible to design sustained release matrix tablets with METHOCEL K15MCR polymer. The polymeric effects on the formulated tablets are evident. The MDT and $t_{50}$ value of the formulated tablets were also satisfactory. However, further investigation is required to establish in-vivo-in-vitro correlation to reveal the accurate pattern of drug release in-vivo environment from this polymeric system.

\section{Acknowledgement}

The authors are thankful to the Silva Pharmaceuticals Ltd. for the generous donation of active ingredient of Carvedilol and giving the chance to work in their plant which was very helpful in accomplishing the project work in time and make it successful. The authors are also thankful to the Department of Pharmacy, Noakhali Science and Technology University for providing laboratory facilities.

\section{References}

1. Alderman, D.A. (1984) A review of cellulose ethers in hydrophilic matrices for oral controlled release dosage form. International Journal of Pharmaceutical Technology \& Product Manufacture, Volume 5, Pages 1-9.

2. Lachman, L., Liberman, H.A., and Kanig, J.L. (1986) The Theory and Practice of Industrial Pharmacy (3rd ed, Pages 430-456). Lea \& Febiger, Philadelphia.

3. Veiga, F., Salsa, T., Pina, M.E. (1988) Oral Controlled Release Dosage Forms II glassy polymers in hydrophilic matrices. Drug Development and Industrial Pharmacy, Volume 24, Pages 1-9. DOI: 10.3109/03639049809082346

4. Kim, H., and Fassihi, R. (1997) Application of binary polymer system in drug release rate modulation. 2 . Influence of formulation variables and hydrodynamic conditions on release kinetics. Journal of Pharmaceutical Sciences, Volume 86, Pages 323-328. DOI: $10.1021 /$ js $960307 p$ 
5. Williams, III R.O., Reynolds, T.D., Cabelka, T.D., et al. (2002) Investigation of excipient type and level on drug release from controlled release tablets containing HPMC. Pharmaceutical Development and Technology, Volume 7, Issue 2, Pages 181-193.

6. Chakraverty, R. (2012) Preparation and evaluation of sustained release microsphere of norfloxacin using sodium alginate. International Journal Pharmaceutical Sciences and Research, Volume 3, Issue 1, Pages 293-299.

7. British Pharmacopoeia. (2000) Her Majesty's stationary office, London, England. Volume 2, Pages 266-268.

8. Korsmeyer, R.W., Gurny, R., Peppas, N.A., et al. (1983) Mechanism of solute release from porous hydrophilic polymers. International Journal of Pharmaceutics, Volume 15, Pages 25-35. DOI: 10.1016/0378-5173(83)90064-9

9. Sato, H., Miyagawa, Y., Okabe, T., et al. (1997) Dissolution mechanism of diclofenac sodium from wax matrix granules. Journal of Pharmaceutical Sciences, Volume 86, Pages 929- 934. DOI: 10.1021/js960221w 